\title{
Healing Obsessive Symptoms Stemming from Twin-Birth with Tandem Hypnotherapy
}

\author{
Vas $\mathrm{JP}^{*}$ and Császár-Nagy $\mathrm{N}$
}

Psychotherapy Department of Borsod University Hospital, Miskolc, Hungary

\begin{abstract}
Ancient myths always had a special role in people's life helping them to deal with pre/perinatal traumatic experiences, which might lead to somato- and psychopathological symptoms. For healing the diseases stemming from this period of human life a new method has been developed by the authors. Tandem is an acronym meaning the Touch of Ancient and New Generations with a Dialogue Experiencing Oneness of Minds (TANDEM). Tandem Hypnotherapy designates a group of hypnotic methods that can be effectively applied in the case of psychosomatic and mental disorders stemming from trans- poly- and inter-generationally mediated traumas. Techniques of Tandem Hypnotherapy have been developed by the authors for the following settings: joint rebirth trance of mother and child; joint con-generational trance of natural or virtual twins; twin hypnosis and certain forms of inter-generational and trans-generational group-hypnotherapy. In the case of all these methods, Tandem Hypnotherapy takes place with the participation of two or more clients with whom the therapists agree to go into hypnosis with the aim of re-living intrauterine experiences and the subsequent birth. In the therapeutic setting touches have a crucial role as they help to resolve the psychopathological outcomes of early relational traumas. This case study demonstrates the healing process of three members of a family with hetero-zygote twins among them. In the discussion some ideas are raised about how implicit somatic memories of pre/perinatal traumas are built into the stress-coping regulation system of the developing personality with a possibility to be repeated again when facing new stress situations.
\end{abstract}

Keywords: Tandem hypnotherapy; Pre/perinatal trauma; Twin-type tandem hypnosis; Healing pathological outcomes

\section{Introduction}

Some thoughts about symbols of intrauterine life \& birth Can you think of Odysseus' journey with the monsters threatening to swallow him and his crew across the "Mare Tenebrosum", the Atlantic Ocean, as a symbol of a particularly heavy child-birthing? Certainly, you can. You may remember the final scene of The Odyssey when Odysseus meets Penelope, and enters the bedroom he has built around a huge tree, which could be interpreted as a symbol of the umbilical cord. The German psychoanalyst, Ludwig Janus [1] suggests that the great myths and tales in all cultures of the world are symbolic accounts of the intrauterine life of men and women. He emphasizes the need to dissolve both professional and social resistances to respect the psychological life of unborn babies. Stories such as Paradise Lost, Atlantis or the Golden Age can be viewed as ones which are prompted by an unconscious desire to be safe within the womb, while stories relating to struggles against the powers of darkness as represented by hell or a dragon, or a wicked witch can be regarded as symbols of coming into the world; the most important coping experience of life.

What can be the use of these types of myths and tales? First, being in the womb means safety in life for which we strive to gain. Second, safety in the womb and coming into the world are regarded as collective experiences of people that are archetypes, which are shared by everyone. Third, the turns in fate in everyday people's lives are transcended to archetypal sorrows and torments lived through by mythical heroes, which by virtue of being universal and common can be easily accepted and dealt with [2]. The Jungian psychologist Jean Shinoda Bolen wrote two brilliant books about the archetypes of our inner God/Goddess $[3,4]$. From a historical point of view tragic fate or illness in the life of ancestors can be repeated in an unusual way both in uterus and when being born [5].

As a matter of fact, this everyday tendency for the pattern of turns of life to be repeated again and again along the lifespan is called recursion, since these patterns have been engraved into our body and psyche through the mother-fetus bonding during the intrauterine phase. Lynda Share cites George Engel and his research group's 30year longitudinal study of Monica, a woman who had been born with congenital atresia of the esophagus. For the first 2 years of life, she was fed of lying on her black with a feeding tube inserted into her stomach. As a child, Monica fed her dolls the same way lying flat...As the years passed, most astonishingly to the Engel's research team, Monica's young daughters began to feed their dolls in this position as well [6]. It is called an inter- or trans-generational trauma when a traumatic turn of life is unconsciously passed on to the next generation [7].

This kind of pathology had already been treated by the 'shamans' of archaic tribes using trance-work. Wolfgang Jilek has reported on an ancient Indian healing rite called „Spirit Dancing” practiced on the Canadian coast of the Pacific Ocean. The members of the rite are gathered into a dark cave under the ground for three days without any food or water available for them. During this incubation period the participants' personality undergoes renewal and revival [8].

In some tribes, during the ceremony the shaman sings the story of origin of the tribe in full detail, which can last for days. As a result of this procedure a special trance state is achieved similar to that of returning to the „time of origin”, which constitutes a „fresh existence free of any corruption", which can be interpreted as a re-birthing symbol [9]. Onno

*Corresponding author: József Pál Vas, Psychotherapy Department of Borsod
University Hospital, Miskolc, Hungary, Tel: +36 30687 2993, +36 46414 544; E-mail: nyelvmuhely.bt@upcmail.hu, vasjozsefpal@gmail.com

Received May 20 2013; Accepted June 04, 2013; Published June 07, 2013

Citation: Vas JP, Császár-Nagy N (2013) Healing Obsessive Symptoms Stemming from Twin-Birth with Tandem Hypnotherapy. Altern Integ Med 2: 120. doi:10.4172/2327-5162.1000120

Copyright: (c) 2013 Vas JP, et al. This is an open-access article distributed under the terms of the Creative Commons Attribution License, which permits unrestricted use, distribution, and reproduction in any medium, provided the original author and source are credited. 
van der Hart wrote about a shaman in South-America, who takes the role of the guardian spirit of laboring women who are struggling in the spiritual world against the destructive demons who want to steal the fetus's soul. The pattern of this spiritual fight is analogous with the course of child-birthing [10].

You can also find a number of intrauterine and birthing symbols in our everyday life. Why do children love to jump into a swimming pool? Why do they love to play hide and seek or tug of wars? These games can be interpreted as symbolic birthing experiences, as can be driving a car, with sitting in uterus and holding on to the umbilical cord, combined with a fantasy of omnipotence. To quote an example of symbolic representations in everyday life, a borderline patient can be mentioned, who was born with partial suffocation and who loved prolonged diving in water in her adolescent period as if she had been employing his birth coping strategies again and again to overcome the threat of suffocation in an unconscious way.

\section{Method: Tandem Hypnotherapy}

In hypnosis fetal experiences from conception till birth can be recalled by means of constructive memory. While the implicit memory makes the re-living of the original visceral-somatic processes possible, such as floating, swimming, or the taste and smell of the amniotic fluid, its friction on the skin or the gentle stroking of the mother, the adult emotional-cognitive evaluative processes make it possible to get these experiences under control. Through dissociation the experience is processed on two levels; on an archaic, undifferentiated brainstem and limbic level, and on an adult, differentiated cortical one [11,12].

When a patient reports on being unwell due to a state of anxiety, this can be regarded as a negative trance state in which visceralsomatic dysfunctions, such as fast heart-beating, hyperventilation, sweating and fear of death evoked by implicit memory predominate both stress-coping and emotional and cognitive evaluative functions; which explains why these patients feel so helpless and vulnerable. In hypnosis however, the therapist controls the recalling of visceralsomatic memories and helps the patient cope with his/her experience with the use of own mature emotional and cognitive operations [13].

In order to increase the efficiency of the therapist's efforts it is desirable to recall the original mother-fetus relationship with the mother also being included in the process, rather than the patient alone. This way the mother should also be able to overwrite the traumatic implicit memory within a joint co-regressive hypnosis with the patient. This type of therapeutic setting is called as Tandem Hypnotherapy developed by the authors a few years ago. Tandem is an acronym, which means Touch of Ancient and New Generations with a Dialogue Experiencing oneness of Minds (TANDEM). Tandem Hypnotherapy (THT) designates a group of hypnotic methods that can be effectively applied in psychosomatic and mental disorders stemming from Tranand inter T generationally mediated traumas. Techniques of THT have been developed by the authors for the following settings: the joint rebirth trance of mother and child; the joint con-generational trance of natural or virtual twins; twin hypnosis and some forms of intergenerational and trans-generational group-hypnotherapy [14-18]. THT involves the participation of more than two persons: the client, the hypnotherapist, and the co-therapist, who can be a professional person (a nurse, an occupational therapist), and the client's relative, e.g. his/ her natural mother. All techniques of THT involve two or more clients with whom the therapists make an agreement as to undertake hypnosis with the aim of re-living intrauterine experiences and the subsequent birth. During THT the co-therapist and the client go into trance while touching each other. However, the hypnotherapist keeps distance. The aim of THT is to elicit a positive, corrective experience with the potential of resolving the client's trauma. Touch is considered to be able to create calmness, safety, and love, which are viewed to be lost or confined by unbearable emotions of prenatal traumas $[19,20]$. Thus the essence of THT seems to be a joint attunement evolving between participants who are in tandem trance. The attunement is viewed to have therapeutic effect because it creates calmness, acceptance and love, which is shared in patient and co-therapist.

We suggest that traumatic sensations and emotions, the origins of which stem from the pre- and prenatal periods, including anxiety, guilt, remorse, phobia, obsession or compulsion, can be transcribed into neutral or good, in the same way as a wrong code can be changed into a right one.

\section{Case Presentation}

This time more than 50 cases are under clinical investigation, which are viewed as suitable to study how the THT works. Here we report on the case of a 27 year old lady, Nancy a teacher who explicitly sought hypnotherapy. She gave birth to two boys, and it was after the birth of the second child that she began to suffer from irrepressible obsessions. These included fears of not being able to swallow automatically, or of not being able to articulate words, or breathe automatically. Furthermore, she had a fear of going mad, or blind, and a fear of outside objects exploding the minute she would look at them, that is of unintentionally destroying the world, and others. All these fears emerged in the presence of retained reality functions as totally bizarre yet constantly recurring thoughts. Nancy was born in a small country town from a twin pregnancy. Her twin sister, let us call her Judy here, had an immature personality, and conducted a self-destructive lifestyle. She didn't finish her schooling and gave the impression of an unborn fetus living up her resources greedily without a need for compensation.

The girls' father, a car mechanic, was a rigid and violent man dominating the whole family, by keeping those who challenged him under control with drunken abuses. His small business has always been successful and he always used excessive control over his wife and daughters. Later he developed Parkinson's disease-which can be regarded as a symbol of the extension of his excessive psychological control to the control of movements-and he died. The mother was a submissive woman who worked as a book keeper, and who was living like a little mouse in her introverted world. She acted like a subordinate to her husband, and was always willing to be dominated and arbitrarily commanded by him. In the business she was in charge of taking orders, handling the customers and all the paperwork.

The girls were looked after by paid babysitters, in line with the father's will. Nancy has clear memories from the time when she was between one and two years old, explaining to Judy that the babysitters were unsuitable and so had to be hated until they leave. And that's how it happened until a pedantic lady turned up who met their expectations and who looked after them as late as their teenage years. Nancy remembers clinging on to her nanny's skirt, begging her not to leave the house because she was dreading the return of her unyielding father from work. When this lady unexpectedly left, they were twelve years old. The next babysitter seemed to ignore the rules of hygiene, and Nancy began to develop disgust towards her. She refused to eat, lost weight and had to be hospitalized on suspicion of acute colitis. Nancy, who was a strong, self assertive person, controlling her environment and putting herself into the center already from a young age, was increasingly becoming compulsively accurate, a perfectionist who excelled with her 
achievements both in academic subjects and in sports. As if to offset her aggression she supported and patronized those close to her, making them her twins, so to say, and organizing their lives. With Judy she did the same. Despite all Nancy's achievements, it was Judy who received more acknowledgements from their father, who regarded her as the brain in the family. Nancy on the other hand was regarded as „only" beautiful. Her first anxiety state developed when she was sixteen and she has had anxiety states accompanied by the symptoms of incomplete torticollis spastica ever since. After being physically abused by the father at the age of sixteen, Nancy moved away from home and never returned. She feels disgust of any object coming from home, and sees it as a source of infection. This sense of disgust has extended to her mother, rendering their relationship permanently tense. Judy's life has been hit by even greater turbulences. She refused to obey her father's will, struck up relationships with men of dubious background, used drugs and alcohol, did not finish her schools and has lived in poverty relying on casual work. Both of Nancy's childbirths were ridden with complications and both boys were in need of longstanding medical care after birth.

As to Nancy's mother's history she was an unwanted child raised in a cold and achievement centered family climate, receiving little love. This handicap she was able to compensate with a life of hard work and diligence. When she became pregnant her husband proclaimed, that they were to have no more than one child. She on the other hand started praying to God: „My Lord, may you give me twins.” In retrospect this can be interpreted as an indication of a knowledge of bearing twins, which was however not allowed into consciousness. Ultrasound examination did not exist at the time, and the gynecologist indicated pregnancy with only one child. When Judy was born it became clear that there was one more baby in the womb. Everybody in the operation room became agitated and one of the gynecologists in the room, stretched her arm deeply in the womb and pulled out the preterm Nancy, who was of very small weight and physically immature. She could not nurse from the breast and showed symptoms of prenatal stress as excessive screaming, apathy, less sleep, increased irritability, states of extreme restlessness $[21,22]$.

During her intrauterine regressive hypnoses Nancy reported on the following experiences: While she perceived herself as an embryo only a few millimeters long, she suddenly noticed a formidable creature occupying the whole space, which was there motionless, and it was impossible to know whether it was dead or alive. In the therapy Nancy started to feel anxious and by using her adult cognitive operations she realized that she felt that perhaps the others were not aware of Judy, and it was her who had to raise her mother's attention by saying, something like: "Mummy, there are two of us."

In the hypnosis she realized in despair that she did not succeed in doing so. When her twin turned to face her, she looked disgusted and frightened. In an awaken state Nancy associated this feeling with her disgust relating to the mother and the home, a womb symbol. In the hypnosis she lived through how the space available for her was becoming smaller and smaller as they were growing, and finally she was forced into a pose in which her back was stretched backwards, a feeling that might have been the underlying cause of torticollis. She felt to be responsible for keeping Judy alive, and this was why she had to help her in being born. This might be the reason why Judy was to be born first. At this point of the hypnosis Nancy felt that she was able to stretch out and relax at last, as she had to stay in order to become mature enough to be born. However, the gynecologist insensitively reached into the womb, seized her leg and her protestation notwithstanding dragged her out into the open. She saw two gynecologists, a young one and another who had white hair, a description which was later confirmed by the mother.

During therapy Nancy's obsessions became more intense, while an actual distress elicited a feeling of shame and social phobia. At this point her mother and sister began to be included in the THT sessions. In the joint sessions with her mother Nancy was reassured that she was not responsible for the fact that Judy was not expected, while the mother could experience that at a deep psychological level she had indeed been aware of having twins and had been looking forward to having them. Judy, like Nancy, exhibited great hypnotic susceptibility, and was able to relive intrauterine experiences already at her first individual hypnosis. Judy reported on elementary sensual experiences, such as the velvet stroking of the amniotic fluid, its viscosity, particular taste, and the waves which caused vibration on her skin and enabled her to communicate with Nancy. When she first noticed that somebody else was also in the womb she was surprised, not knowing first what it was she swam over to it, and found her cute and wanted to play with her. However, Nancy was not a partner, as she was so immature since might have been conceived later than Judy. On the therapist's suggestion she chose a guardian spirit, a dolphin, who helped her in being born by leading the way and exploring the birth canal, and Judy followed her. When she was born, she sent the dolphin back to help Nancy too.

This was followed by Nancy's and Judy's joint trance during which Nancy kept being passive, letting her twin take the initiative. Later Nancy explained that she would have had a passive nature had the intrauterine context not demanded strong activity from her; the organizing and governing of other people's life. Judy on the other hand realized that she had to initiate contact with her mother, if she wanted her to know about her existence. During the next therapeutic session all three of them got into a joint trance. In order to transcribe traumatic events, they attempted to again live through every single event in the most natural way. It was very interesting to see how-in the wake of a therapeutic intervention following their being born-they jointly recollected events of their lives at 2, 5,10, 20 and 40 years of age, in the spirit of positive change. During a future pacing Nancy was preoccupied with her school-age children, while Judy, wearing an elegant costume, was organizing some company event, talking on her mobile.

\section{Discussion: Interpretations of Nancy's Psychotherapy with THT}

As the treatment was centered on Nancy's problems, we would like to give a short account relating to the interpretation of her illness. The precise etiology of the obsession was revealed during the conducted THT sessions. According to Roland Fischer thinking is rooted in movement, as he put it "experience of moving is a moving experience" [23]. This idea gets support from the fact that the neural pathway of thinking and movement control is equally the cortico-thalamo-cerebellar circuitry, the subcortical section of which is already in operation in the fetal phase [24]. It is logical to assume that self-generated movement can only be designed by anticipating its outcome.

What was the course of development concerning the interaction between Nancy's self-generated movement and thinking when she was around 10 weeks old after conception? As she was growing, her movements were increasingly hindered by the presence of a presumably bigger and more mature twin, Judy. In the joint tandem trance involving Nancy and Judy, Nancy's feeling of being pushed out were successfully overwritten by an intervention suggesting that the fact that the mother knew about Judy's existence meant that Judy had a right for being, so 
she did not need to take over Nancy's space in order to call the mother's attention to herself. On an unconscious level the mother expected two babies which meant that Judy and Nancy equally had the right for being. Nancy must have had serious doubts not only considering the hindrance of her movements but also her right for being. "So who is it now, who exists, who has the right to be, her or me? Am I supposed to move at all? Can I show the signs of living? May I call attention to myself, and do I deserve to live at all, or should I quietly let her take away resources and die?" This grave doubt is still manifest in her existential anxiety, and in her obsessions, sense of disgust and social phobia. Her obsessions revolve around life and death; "Can I breathe, that is can I move? Can I speak, that is can I communicate?" "Can I and am I permitted to live?", "If not, may the world be destroyed, may everything I look at explode, including Judy!" Murderous aggression possibly elicited instant guilt and through reaction formation caring love, as demonstrated by her overprotective and charitable behavior. At the same time, her rejection of the womb carried a kind moral judgment, as if saying "I reject you as you have not acknowledged my right for being!” [25].

A hypothesis based on evolutionary psychology provides us with further insights contributing to the interpretation of aggressive urges. Following MacLean's idea Ricarda Müssig [26] put forward the proposal that the first trimester is characterized by the territorial instinct domain of the fish-reptile phase in phylogeny. The baby reptiles, following a short period of maternal care acquire a territory of their own, attacking and killing strangers transgressing the territory's borders even if coming from the same brood, or alternatively they flee away. Then in the second trimester the emotional bond which is being formed between mother and fetus makes the murderous aggression and persecutory anxiety of the reptile phase to be overwritten. However, the dramatically intense impulses may stay on at the most primitive level of the mind's functioning like fossils to be integrated into an unconscious dynamic representation of an expectation suggesting that the important other would relate to her or him in a similarly exploitative or persecutory manner. This hypothesis offers an alternative interpretation for the disgust Nancy felt, namely an emotional self-reflection on archaic hatred stemming from the fetal reptile phase [27].

After THT was finished an individual psychotherapy was continued. During the three year course of the therapy regarding the symptoms, it displays a fluctuating course with a strong tendency of improvement. Nancy's obsessions, torticollis and social phobias still appear in stress situations, but she has increasingly more effective means to overcome them. Now she is symptomless taking an anxiolytic drug of minimal dose. Her relationship with her mother has become more harmonious, and her sense of disgust towards her has considerably diminished. No doubt, her personality has become more mature, her handling of aggression, her empathic skills have both greatly improved while her need to control others and her perfectionism has decreased. She has become more open to emotionally mutual relationships than she was before. She would simply like to become an emotionally harmonious and contented woman, and is eager not to pass on the gloomy intrauterine experiences which she integrated into her character.

\section{Conclusion: Fetal Implicit Memory as a Self-Similarity- Fractal-Principle}

The psyche seems to be in possession of an inner "imaging method" with the help of which even the earliest experiences are able to be recalled. Since the function of conscious memory does not emerge until the age of three, early experiences, including fetal ones can only be recalled as unconscious, bodily, mainly visceral-somatic sensations and (dys) functions called implicit memory. For instance, a young woman's miscarriage could be understood as a manifestation of the implicit memory of a sense of guilt her mother had felt due to her abortion at the time the young woman was conceived. There are several cases of women, where both they and their mothers were born with Cesarean section [28].

Consequently, the psyche is able to remember fetal stress situations when faced with regulatory dysfunctions similar to those in the fetal condition [29]. The impact of the traumas suffered in the fetal phase is shown to be the incorporation of the fetus's response to stress into its regulative processes, its coping system and in particular into its coping with stress, with a consequence of deforming or idiosynchratically modifying them [30]. Severe or recurring traumas such as attempted abortion or neglect might result in the structural damage of the brainstem and the limbic system, and in synaptic pruning which results in reduced synaptic connections among the various areas of the brain. These damages may then be manifested in extrauterine life as chronic deficiencies of psycho-autonomous regulation, in somatic illnesses, or in psychosomatic and psychic disorders $[31,32]$.

Implicit memory seems to be characterized by a fractal or selfsimilarity principle, whereby it is able to be repeated and multiplied at the various hierarchic levels of personality-functioning. Fractal refers to an organizing principle of our emotional and cognitive processes, characterized by a capacity of creating unconscious working models, with which we will be primed towards future experiences by experiences not yet consciously experienced in the past outside the womb; which results in the fact that, "we can remember the future", so to say $[33,34]$.

By virtue of the implicit memory the mind remembers the early stress situation in a way that the actual stress situation precipitates the original visceral-somatic dysfunction which was brought about in the fetal age by the original damage.

In this sense implicit memory represents a defective mechanism of self-regulation relating to the historical and relational dimensions of human life, which activates identical deficient processes in all situations which are analogous with that in which the original damage occurred. For example, when a prolonged labor complicated with suffocation has formed the base of the implicit memory, the memory might be evoked later in distress situations either as a fear of suffocation, or cardiac arrest or panic attack or agoraphobia (which can be the bodily memory of coming out of the birth canal to the threatening open space of extrauterine life) or claustrophobia (which in turn can be seen as the implicit memory of the fear of being locked into the narrow and engulfing birth canal) [35].

To sum up, THT can be viewed as a special hypnotherapy context in which archaic visceral-somatic patterns of experiences leading to later suffering in life can be worked on through with the help of the therapist and the co-therapist-a healing team-who are able the cooperate for the client's benefit in order for the implicit somatic memory stemmed from fetal trauma to be resolved.

\section{References}

1. Janus L (2002) Current Status of Research in Prenatal Psychology and Prenatal Psychology-Based Psychotherapy. Janus L (Ed.). The Significance of the Earliest Phases of Childhood for Later Life and for Society. ISPPM, Heidelberg 29-32.

2. Jung CG (1978) Man and his Symbols. Picador, London.

3. Bolen JS (1989) Goddesses in Everywoman. HarperCollins, New York 
Citation: Vas JP, Császár-Nagy N (2013) Healing Obsessive Symptoms Stemming from Twin-Birth with Tandem Hypnotherapy. Altern Integ Med 2: 120. doi: $10.4172 / 2327-5162.1000120$

Page 5 of 5

4. Bolen JS (2003) Gods in Everyman, Archetypes That Shape Men's Lives. HarperCollins, New York.

5. Rand M (1999) As It Was in the Beginning: The Significance of Infant Bonding in the Development of Self and Relationships. The International Journal of Prenatal and Perinatal Psychology and Medicine 11: 487-494.

6. Share L (1996) Dreams and the Reconstruction of Infant Trauma. The International Journal of Prenatal and Perinatal Psychology and Medicine 8: 295-316.

7. Vas JP (2006) Terror natus est. Upon the Concept, Recognition, and Healing of Trans-generational Trauma in the Counseling Practice. Confessio 30: 13-25.

8. Jilek WG (1988) Indian Healing. Hancock, Surrey, Canada.

9. Eliade M (1964) Shamanism: The Archaic Techniques of Ecstasy. Pantheon Books, New York.

10. Hart Ovd (1983) Rituals in psychotherapy. Irvington Publishers, New York.

11. Seelig M (1998) Re-experiencing Pre- and Perinatal Imprints in Non-Ordinary States of Consciousness. The International Journal of Pre- and Perinatal Psychology and Medicine 10: 323-342.

12. Verny TR (1996) Isolation, Rejection and Communication in the Womb. The International Journal of Pre- and Perinatal Psychology and Medicine 8: 287294.

13. Lynn SJ, Rhue JW (1991) An Integrative Model of Hypnosis. In Lynn SJ, Rhue J W (Edn) Theories of Hypnosis: Current Models and Pesrpectives. The Guilford Press, New York 397-438.

14. Vas JP, Császár N (2011a) Transnatal Tandem Hypnotherapy (TTH): A New Method for Resolving Prenatal Traumas. International Journal of Psychotherapy 15: 55-64.

15. Vas JP, Császár N (2011b) Multipersonal Tandem Hypnotherapy (MTH): A New Method for Resolving Intergenerational Traumas. International Journal of Psychotherapy 15: 38-48

16. Vas JP, Császár N (2013a) Tandem Hypnotherapy. International Body Psychotherapy Journal. The Art and Science of Somatic Praxis 12: 74-86.

17. Vas JP, Császár N (2013b) Tandem Hypnotherapy for Resolving Late Consequences of Prenatal Traumas. Journal of Traumatic Stress Disorders \& Treatment. Under submission.

18. Császár-Nagy N, Vas JP (2013) Tandem Hypnotherapy for Healing Prenatal Traumas. International Journal of Clinical and Experimental Cardiology. Under submission.

19. Heller S (1997) The Vital Touch. How Intimate Contact With Your Baby Leads To Happier, Healthier Development. Henry Holt and Company, New York.

20. Hermann I (1934/1984) Primordial Instincts of Man. Magveto, Budapest.
21. Janus L (1997) The Enduring Effects of Prenatal Experience. Jason Aronson, London.

22. Sandbank AC (1999) Twin and triplet psychology. Routledge, London.

23. Fischer R (1986) Toward a neuroscience of self-experience and states of selfawareness and interpreting interpretations. In: Wolman BB, Ullman M (Eds.). Handbook of States of Consciousness. Van Nostrand Reinhold, New York $3-30$

24. Andreasen NC, Paradiso S, O'Leary DS (1998) "Cognitive dysmetria" as an integrative theory of schizophrenia: a dysfunction in cortical-subcorticalcerebellar circuitry? Schizophr Bull 24: 203-218.

25. Kafkalides AZ (1980) The Knowledge of the Womb. Triklino House, Corfu.

26. Müssig R (1995) Mother Scheme, Rival Scheme and Ethogenetic Rule. The International Journal of Prenatal and Perinatal Psychology and Medicine 7: 419-436.

27. Seguí MC (1995) The Prenatal Period as the Origin of Character Structures. The International Journal of Prenatal and Perinatal Psychology and Medicine 7: 309-322.

28. Dowling $T$ (2002) Beyond the Birth Trauma. In Janus L (Edn) The Significance of the Earliest Phases of Childhood for Late Life and for Society. ISPPM, Heidelberg 25-28.

29. Turner J, Turner-Groot T (1999) Prebirth Memory Discovery in Psychotraumatology. The International Journal of Pre- and Perinatal Psychology and Medicine 11: 469-485.

30. Verny TR (2002) The Importance of Prenatal and Perinatal Psychology to the Health of Future generations. In Janus $L$ (Edn) The Significance of the Earliest Phases of Childhood for Later Life and for Society. ISPPM, Heidelberg 121124.

31. Bergh Bvd (2002) The effect of maternal stress and anxiety in prenatal life on fetus and child. In: Janus $L$ (Ed.). The Significance of the Earliest Phases of Childhood for Later Life and for Society. International Society of Prenatal and Perinatal Psychology and Medicine (ISPPM), Heidelberg 37-46.

32. Siegel DJ (1999) The Developing Mind. Toward a Neurobiology of Interpersona Experience. The Guilford Press, New York.

33. Fedor-Freybergh PG (2002) Prenatal and Perinatal Psychology and Medicine New Interdisciplinary Science in the Changing World. In Janus L (Edn) The Significance of the Earliest Phases of Childhood for Later Life and for Society. ISPPM, Heidelberg 11-23.

34. Stern DN (2004) The Present Moment in Psychotherapy and Everyday Life Norton \& Company, New York.

35. Gabbard GO (1994) Psychodynamic Psychiatry in Clinical Practice. American Psychiatric Press, Washington DC. 